\title{
Caracterização das vazões em uma pequena bacia hidrográfica do Distrito Federal, Brasil
}

\author{
Fernanda A. 0. de Souza ${ }^{1}$, Cícero L. da Silva ${ }^{2}$, \\ Selma R. Maggiotto ${ }^{2} \&$ Manuel $P$. de Oliveira Júnior ${ }^{2}$
}

\begin{abstract}
RESU M O
No Brasil, a região do Distrito Federal é caracterizada pela presença de córregos e pequenos rios, o que torna importante a caracterização das vazões em microbacias. U tilizando uma série de 13 anos provenientes da microbacia do córrego da Capetinga, foram analisadas: a estacionariedade de parâmetros hidrológicos; as distribuições estatísticas que melhor representam a vazão; a aplicação de séries curtas versus séries médias no cálculo de vazões; e a necessidade de pedido de outorga para o uso da água, de acordo com a legislação vigente. As distribuições Lognormal 3 e Pearson 3 foram as que melhor representaram a série de vazões máximas, enquanto que Logpearson 3 foi a distribuição mais indicada para a vazão mínima. A precipitação total anual, a vazão média de longa duração e a vazão mínima apresentaram séries estacionárias, diferentemente da vazão máxima instantânea. 0 uso de séries curtas para o cálculo de vazões na microbacia estudada não se mostrou adequado, já que gerou a superestimativa das vazões mínimas e a subestimativa das vazões máximas. De acordo com a legislação, captações no córrego Capetinga exigem pedidos de outorga à agência reguladora, apesar de a vazão mínima apresentar baixa magnitude, o que reflete no baixo potencial de exploração do córrego.
\end{abstract}

Palavras-chave: distribuição de probabilidade, estacionariedade, uso da água

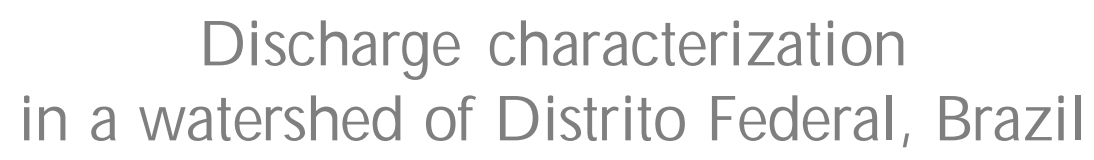

\begin{abstract}
In Brazil, Distrito Federal region is characterized by the presence of streamlets and small rivers, which explains the importance of the discharge characterization in watersheds. This study used 13 years of hydrological data of the Capetinga watershed to analyze: the stationarity of hydrological parameters; the statistical distributions that best represent the discharge; the comparison of using short and medium series to calculate discharge; and the requirement for water rights concession according to the current legislation. The Lognormal 3 and Pearson 3 distributions best represented the maximum discharge, while Logpearson 3 distribution was best indicated for minimum discharge. Total annual precipitation, long duration mean discharge and seven-day minimum flow presented stationary series, but maximum instantaneous discharge did not. The use of short series to calculate discharge in this watershed was not reasonable, since it resulted in overestimation of the minimum discharge and underestimation of the maximum discharge. According to the legislation, the water capturing from the stream Capetinga requires a concession from the regulatory agency, in spite of the minimum discharge has a small value, which reflects its low potential of use.
\end{abstract}

Key words: probability distributions, stationarity, water use

\footnotetext{
${ }^{1}$ Agência N acional de Águas. Setor Policial, Área 5, Quadra 3, Blocos "B", "L" e "M ", CEP 70610-200, Brasília, DF. Fone: (61) 2109-5417. E-mail: abreu.fernanda@uol.com.br

${ }^{2}$ Faculdade de Agronomia e Medicina Veterinária da Universidade de Brasília. Campus U niversitário Darcy Ribeiro, Asa N orte, CEP 70910-900, Brasília, DF. Fone: (61) 3107-6628. E-mail: cicero@unb.br; srmaggio@unb.br; manueljr@unb.br
} 


\section{INTRODUÇÃO}

A região do Distrito Federal (DF) é chuvosa, com totais médios anuais variando entre $1360 \mathrm{~mm}$, na parte oeste da região e, aproximadamente, $1500 \mathrm{~mm}$ no centro (Dornelas et al., 2006). De acordo com os mesmos autores, o clima da região é do tipo Cwa segundo a classificação climática de Köppen: mesotérmico, com inverno seco e verão quente e chuvoso. Alencar et al. (2006) descreve o DF como uma região de nascentes, caracterizada pela presença de córregos e pequenos rios. Apesar de ter seus cursos de água perenes, verifica-se uma redução muito grande da vazão no final do período de seca, que se estende de abril a outubro.

A disponibilidade hídrica por habitante no DF é baixa (Rebouças et al., 1999), e é agravada pelo uso da água para a irrigação. No final da década de 90, a área irrigada do DF atingiu aproximadamente 12000 ha, com uma captação de água de 12 $\mathrm{m}^{3} \mathrm{~s}^{-1}$ nos dias de maior demanda (Silva, 2003).

Face ao exposto, nota-se a importância de se realizar uma gestão eficiente dos recursos hídricos no DF. Estudos de estacionariedade de vazões e o uso de distribuições estatísticas adequadas aos eventos extremos de vazão podem ser considerados ferramentas imprescindíveis para se alcançar esse objetivo.

No Brasil, estudos relativos à mudança de comportamento de séries temporais de vazão e de precipitação são encontrados em Groppo et al. (2005) e Müller et al. (1998). Os primeiros autores concluíram que, na Bacia do Rio Piracicaba, estado de São Paulo, as precipitações apresentaram uma tendência de aumento, enquanto que as vazões apresentaram uma tendência de diminuição em função das captações realizadas pela companhia de saneamento do Estado. Na análise das vazões afluentes ao reservatório de Itaipu e da precipitação nas respectivas bacias hidrográficas, Müller et al. (1998) concluíram que tanto a precipitação quanto as vazões apresentaram tendências de elevação.

$\mathrm{Na}$ Inglaterra, num estudo para verificar tendências de alteração das vazões mínimas, Hannaford \& Marsh (2006) observaram uma leve tendência de diminuição da vazão mínima em algumas bacias hidrográficas do país devido à diminuição das abstrações ao longo dos anos.

Buscando determinar a distribuição estatística que melhor se adapta às vazões máximas em 44 bacias hidrográficas da Turquia, Haktanir (1992) testou 12 distribuições estatísticas e concluiu que os melhores resultados foram verificados com o uso das distribuições Lognormal de 2 e 3 parâmetros e com a distribuição de Gumbel. Leme (2002) e Silva (2003) também verificaram um ajuste muito bom da distribuição de Gumbel numa série de eventos máximos em uma microbacia do DF.

Leme \& Chaudhry (2005) testaram as distribuições de Gumbel e de Weibull na determinação da vazão mínima com sete dias de duração e período de retorno de dez anos $\left(\mathrm{Q}_{7,10}\right)$ no vale médio do rio Jaguari Mirim, estado de São Paulo, concluindo que o ajuste dado pela distribuição de Weibull foi superior ao ajuste da distribuição de Gumbel.

Analisando 1505 séries de vazões mínimas nos Estados Unidos da América com o uso de diversas distribuições estatísticas, Kroll et al. (2002) concluíram que as distribuições de Pearson tipo 3 e a Lognormal 3 foram as que melhores se adaptaram ao estudo. De acordo com Reilly \& Kroll (2003) e Kroll et al. (2004), nos Estados Unidos da América, o USGS (United States Geological Survey) sugere o uso do parâmetro $\mathrm{Q}_{7,10}$ obtido a partir da distribuição Logpearson 3 para se estudar as vazões mínimas, muito embora os mesmos autores afirmem que naquele país não há consenso quanto a melhor distribuição para esse parâmetro. Para a análise de vazões mínimas no Brasil, na maioria das vezes são utilizados dois parâmetros: a $\mathrm{Q}_{7,10}$ e a vazão com permanência de $90 \%\left(\mathrm{Q}_{90}\right)$ ou de $95 \%\left(Q_{95}\right)$. Silva et al. (2006) encontraram que a distribuição que melhor representou a $\mathrm{Q}_{\min }$ anual e $\mathrm{Q}_{7,10}$ na região do Alto Rio Grande, em MG, foi a Lognormal 3.

Estudos hidrológicos em grandes rios são comuns em nosso país tendo em vista o interesse do setor elétrico, porém a captação de água na região do DF é feita predominantemente em pequenos córregos. O desenvolvimento de atividades diversas dentro das médias e pequenas bacias hidrográficas, com o consequente aumento da demanda de água dos corpos d'água, torna-se cada vez mais importante a adequada gestão do uso da água, como demonstrado por modelos que utilizam dinâmica de sistemas (Sánchez-Román et al., 2009). A regulamentação legal para a implementação do instrumento de outorga do uso da água no DF surgiu em 2001 (Decreto n. 22.359 de 31 de agosto de 2001). De acordo com o artigo $17^{\circ}$ do decreto citado, a disponibilidade hídrica deverá ser estabelecida em função de características hidrológicas da bacia sobre a qual incide a outorga. Porém esta caracterização hidrológica ainda é incipiente para microbacias do DF.

Dessa maneira, evidencia-se a importância de estudar as características das vazões em pequenas bacias hidrográficas do DF. Diante disso, e por ser uma área de preservação ambiental, escolheu-se como objeto de estudo o córrego Capetinga, destacando os seguintes objetivos: verificar a estacionariedade nos parâmetros precipitação total anual, vazão média de longa duração, vazão mínima com sete dias de duração e vazão máxima instantânea; verificar as distribuições estatísticas que melhor se adaptam às séries de vazões máximas e mínimas; comparar valores ajustados a uma série curta e a uma série média de vazão; e verificar a possibilidade de outorga de água para irrigação na Fazenda Experimental Água Limpa em função da vazão média mínima mensal, da $\mathrm{Q}_{90}$ e da $\mathrm{Q}_{7,10}$.

\section{Material e MÉTOdos}

\section{Descrição da microbacia}

O presente estudo foi realizado na microbacia do córrego Capetinga, localizada no Sudeste do Distrito Federal, região Centro-Oeste do Brasil, e cuja foz corresponde à latitude $15^{\circ}$ $56^{\prime} 15^{\prime \prime}$ S e longitude $47^{\circ} 56^{\prime} 16^{\prime \prime} \mathrm{W}$. Esta microbacia está dentro da Fazenda Experimental Água Limpa patrimônio da Universidade de Brasília, e inserida na sub-bacia do Lago Paranoá (Figura 1A), que por sua vez pertence à Bacia Hidrográfica do Rio Paraná.

O córrego Capetinga se estende por $2,81 \mathrm{~km}$ ao longo da microbacia, que possui área total de $9,62 \mathrm{~km}^{2}$, delimitada por um perímetro de $12 \mathrm{~km}$ e posicionada entre 1057 e $1200 \mathrm{~m}$ de 
altitude. A sua rede de drenagem apresenta aproximadamente $18,19 \mathrm{~km}$, resultando numa densidade de drenagem igual a 1,89 $\mathrm{km} \mathrm{km}^{-2}$. A declividade média da área é de 3,3\%, enquanto a declividade média do leito do córrego é de 1,8\%. Já o coeficiente de compacidade da microbacia (Kc) foi determinado em 1,09 (Alencar et al., 2006). A descrição dos diversos tipos de solo da área pode ser encontrada em Silva \& Oliveira (1999), e a cobertura vegetal, além do mencionado pelos autores, está detalhada na Figura 1B, onde se vê a predominância de campo cerrado e a presença de mata de galeria próximo às margens do curso de água principal.

A.

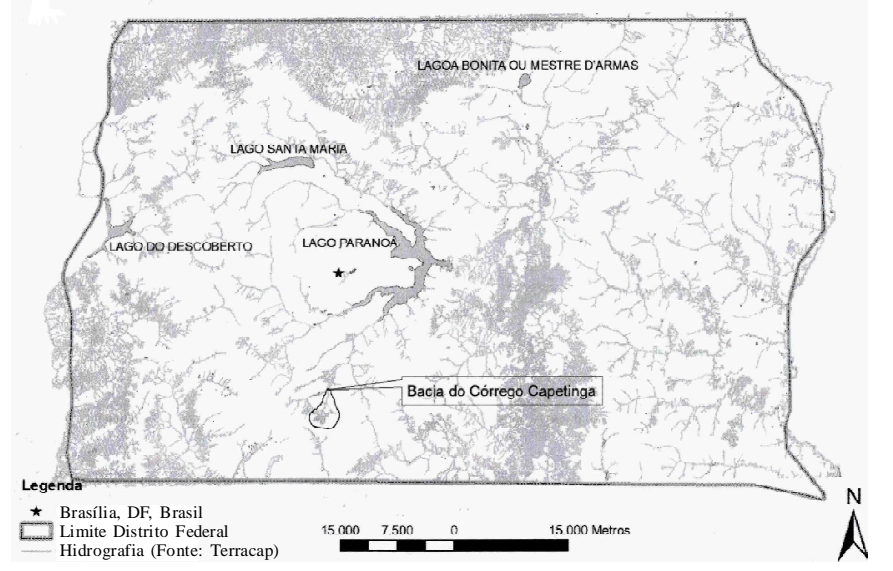

B.

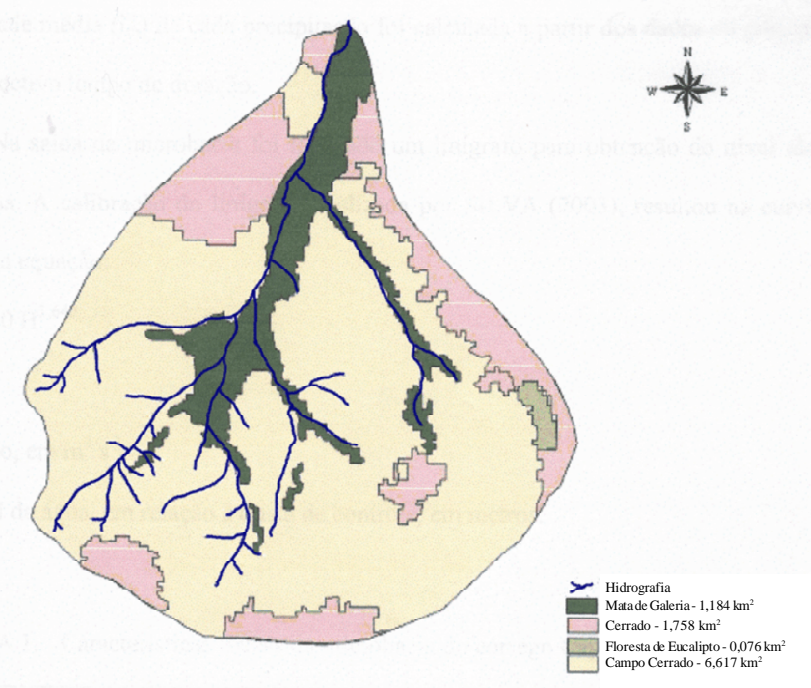

Figura 1. Visualização da microbacia do córrego Capetinga na hidrogafia do D istrito Federal (A), e mapa de cobertura vegetal $(B)$

O clima na região é do tipo tropical de savana caracterizado pela existência nítida de duas estações: uma chuvosa e quente, entre outubro e abril, e outra fria e seca, entre maio e setembro (Alencar et al., 2006). As características de clima e solo da bacia do córrego Capetinga são semelhantes às da maioria das microbacias hidrográficas do Distrito Federal. Portanto, estudos hidrológicos nesta microbacia são importantes pois possibilitam, por meio das vazões específicas, a transferência de dados para outras bacias onde não se têm registros. Além do mais, a captação de água para irrigação de experimentos da Fazenda Experimental é feita logo abaixo da estação hidrológica do córrego. Por isso a identificação de parâmetros de vazão mínima são importantes dada a exigência da agência de controle local para a concessão da outorga.

\section{Obtenção dos parâmetros pluviométricos e fluviométricos}

Foram instalados três pluviógrafos devidamente distribuídos para se medir a precipitação na microbacia. Próximo à fronteira oeste da microbacia existe uma estação meteorológica, que representou mais um ponto de medida da precipitação. As quatro medidas de precipitação possibilitaram o cálculo da precipitação total anual média da microbacia $\left(\mathrm{P}_{\text {total }}\right)$ pelo método de Thiessen, conforme sugerido por Chow et al. (1988).

Para obtenção da vazão instalou-se um controle artificial do nível de água na saída da microbacia, semelhante a um vertedor de barragem, cuja finalidade foi propiciar uma referência fixa para medição da altura de água, conforme o descrito por Silva \& Oliveira (1999).

A medição dos parâmetros foi iniciada em outubro de 1996 e, para este estudo, foi finalizada em junho de 2009, gerando uma série histórica de 13 anos hidrológicos de dados pluviométricos e fluviométricos com início em 1996/1997 e final em 2008/2009. Foi estabelecido o início do ano hidrológico em $1^{\circ}$ de julho e o fim em 30 de junho. A série histórica do córrego Capetinga apresenta falhas somente nos três primeiros meses de registro (julho, agosto e setembro) do primeiro ano hidrológico 1996/1997.

A série de dados fluviométricos foi utilizada na obtenção dos valores de: vazão mínima com sete dias de duração e período de retorno de 10 anos $\left(\mathrm{Q}_{7,10}\right)$, vazão de permanência com $90 \%$ de probabilidade $\left(\mathrm{Q}_{90}\right)$, vazão média das mínimas mensais $(Q)$, vazão média de longa duração $\left(Q_{\text {mld }}\right)$ e vazão máxima instantânea $\left(\mathrm{Q}_{\text {maxinst }}\right)$.

\section{Distribuições estatísticas para as séries de vazões máximas e mínimas}

Inicialmente verificou-se a estacionariedade da série histórica com nível de significância de 5\%, utilizando o teste t de Student, conforme sugerido por Müller et al. (1998) e Sousa et al. (2009), aos seguintes parâmetros: $P_{\text {total }}, Q_{\text {mld }}, Q_{7}$ e $Q_{\text {maxinst }}$.

Para o conjunto de dados de eventos máximos foram testadas as seguintes distribuições: Gumbel, Pearson 3, Logpearson 3, Lognormal 2 e Lognormal 3. Já para os eventos mínimos, foram testadas as distribuições Weibull, Pearson 3, Logpearson 3, Lognormal 2 e Lognormal 3. O estudo foi feito utilizando o software SisCAH 1.0 (Sousa et al., 2009), que também descreve as metodologias de estimativa das distribuições estatísticas e de obtenção dos intervalos de confiança utilizados. Neste trabalho foi utilizada a série das $\mathrm{Q}_{\text {maxinst }}$ para representar os eventos máximos e a série das $\mathrm{Q}_{7}$ para representar os eventos mínimos.

Para a escolha da distribuição mais adequada a cada série foi utilizado, com um nível de probabilidade de 95\%, o valor dos intervalos de confiança superior e inferior de cada 
distribuição, calculados conforme Kite (1988) que considera a distribuição que resultou na menor variação entre esses intervalos como sendo a de melhor ajuste.

\section{Comparação entre uma série curta e uma série média de vazão}

No Brasil, séries de vazões em pequenos córregos geralmente são curtas. Por isso no intuito de verificar a discrepância entre os resultados gerados ao se usar uma série curta de vazão em detrimento de uma série de maior duração, fez-se neste estudo uma comparação entre os parâmetros obtidos a partir de uma série curta (1996/1997 a 2001/2002 - 6 anos) com os obtidos a partir de uma série média (1996/1997 a 2008/2009- 13 anos). As vazões analisadas foram: $\mathrm{Q}_{7} \mathrm{e} \mathrm{Q}_{\text {maxinst }}$ para os períodos de retorno 5, 10, 20, 50 e 100 anos, e $Q_{\text {mdl }}$.

\section{Possibilidade de outorga de água no córrego Capetinga}

$\mathrm{Na}$ análise dos pedidos de outorga para uso de água superficial, a ADASA (Agência Reguladora de Águas, Energia e Saneamento Básico do Distrito Federal) leva em consideração o somatório das vazões a serem outorgadas em um mesmo curso de água e a definição de usos insignificantes. No caso do somatório das vazões, a outorga não poderá exceder: (i) oitenta por cento das vazões de referência $\mathrm{Q}_{7,10}, \mathrm{Q}_{90}$, ou $\mathrm{Q}$, quando não houver barramento; (ii) oitenta por cento das vazões regularizadas dos lagos naturais ou de barramentos implantados em mananciais perenes; (iii) os limites dos itens (i) e (ii) podem atingir um valor correspondente a $90 \%$ da vazão de referência quando se tratar de abastecimento humano. A definição de usos insignificantes está relacionada aos usos individuais de até $1 \mathrm{~L} \mathrm{~s}^{-1}$ (desde que o somatório dos usos individuais não exceda vinte por cento da vazão outorgável) e as acumulações de água com volume máximo de $86400 \mathrm{~L}$ independem de outorga.

Tendo como base esses instrumentos legais, analisou-se a possibilidade de outorga de vazão a partir dos valores das vazões mínimas de referência $\left(\mathrm{Q}_{7,10}, \mathrm{Q}_{90} \mathrm{e} \mathrm{Q}\right)$.

\section{RESULTADOS E DISCUSSÃO}

Na Tabela 1 são apresentados os dados de precipitação total anual para a série histórica de 1996/1997 a 2008/2009. A precipitação média anual na microbacia foi de $1414 \mathrm{~mm}$, com desvio-padrão de 187,25 mm e erro relativo de 13,24\%.

A vazão média de longa duração para série estudada (1996/ 1997 a 2008/2009) do córrego Capetinga foi de $0,1670 \mathrm{~m}^{3} \mathrm{~s}^{-1}$, sendo que seus valores mensais estão apresentados na Tabela 2. Nota-se que os maiores valores dessa vazão ocorreram nos meses de novembro a abril, coincidindo com o período da estação chuvosa no DF. A maior vazão média mensal de longa duração corresponde ao mês de março $\left(0,352 \mathrm{~m}^{3} \mathrm{~s}^{-1}\right)$ e a menor ao mês de setembro $\left(0,041 \mathrm{~m}^{3} \mathrm{~s}^{-1}\right)$.

Ao longo da série histórica, os menores valores da vazão mínima com sete dias de duração $\left(\mathrm{Q}_{7}\right)$ (Tabela 2) ocorreram principalmente no mês de outubro, com a ocorrência de 8 eventos. Os outros aconteceram em setembro (3 eventos) e novembro (2 eventos). Esses meses coincidem com período de transição entre a época seca e a época chuvosa na região do
Tabela 1. Precipitação total anual $\left(\mathrm{P}_{\text {total, }}\right.$ em $\left.\mathrm{mm}\right)$ e precipitação média anual correspondente ao período de 1996/ 1997 a 2008/2009

\begin{tabular}{cc}
\hline Ano hidrológico & $\mathbf{P}_{\text {total }}$ \\
$1996 / 1997$ & 1369 \\
$1997 / 1998$ & 1458 \\
$1998 / 1999$ & 1021 \\
$1999 / 2000$ & 1598 \\
$2000 / 2001$ & 1498 \\
$2001 / 2002$ & 1279 \\
$2002 / 2003$ & 1180 \\
$2003 / 2004$ & 1696 \\
$2004 / 2005$ & 1465 \\
$2005 / 2006$ & 1452 \\
$2006 / 2007$ & 1579 \\
$2007 / 2008$ & 1532 \\
$2008 / 2009$ & 1260 \\
\hline Média anual & 1414 \\
\hline
\end{tabular}

Tabela 2. Vazões médias mensais $\left(\mathrm{m}^{3} \mathrm{~s}^{-1}\right)$ e vazões médias mínimas com sete dias de duração $\left(Q_{7}, \mathrm{~m}^{3} \mathrm{~s}^{-1}\right)$ do córrego Capetinga para uma série de 13 anos

\begin{tabular}{lcc}
\hline \multicolumn{1}{c}{ Mês } & Vazão média mensal & $\mathbf{Q}_{\mathbf{7}}$ \\
Julho & 0,0604 & 0,033 \\
Agosto & 0,0466 & 0,026 \\
Setembro & 0,0411 & 0,023 \\
Outubro & 0,0541 & 0,025 \\
Novembro & 0,1409 & 0,028 \\
Dezembro & 0,2183 & 0,051 \\
Janeiro & 0,2854 & 0,070 \\
Fevereiro & 0,3379 & 0,040 \\
Março & 0,3522 & 0,106 \\
Abril & 0,2375 & 0,086 \\
Maio & 0,1344 & 0,055 \\
Junho & 0,0878 & 0,043 \\
\hline
\end{tabular}

DF e por isso estão associados a eventos de vazões mínimas. No cálculo da $\mathrm{Q}_{90}$ usando a metodologia proposta por Tucci (2002), encontrou-se um valor de vazão de $0,037 \mathrm{~m}^{3} \mathrm{~s}^{-1}$, enquanto $Q$ foi de $0,049 \mathrm{~m}^{3} \mathrm{~s}^{-1}$.

Os valores da vazão máxima instantânea anual são apresentados na Tabela 3, com o valor médio de 11,797 $\mathrm{m}^{3} \mathrm{~s}^{-1}$. A maior frequência de ocorrência desses eventos foi no mês de março (6 eventos), seguido por janeiro ( 3 eventos) e fevereiro

Tabela 3. Vazão máxima instantânea $\left(Q_{\text {maxinst }}\right) \mathrm{em} \mathrm{m}^{3} \mathrm{~s}^{-1}$ do córrego Capetinga para uma série de 13 anos e data de ocorrência dentro do ano hidrológico

\begin{tabular}{ccc}
\hline Ano & Data & $\mathbf{Q}_{\text {maxinst }}$ \\
$1996 / 1997$ & $18 / 03 / 1997$ & 9,16 \\
$1997 / 1998$ & $20 / 03 / 1998$ & 8,59 \\
$1998 / 1999$ & $17 / 11 / 1998$ & 4,62 \\
$1999 / 2000$ & $18 / 01 / 2000$ & 15,61 \\
$2000 / 2001$ & $05 / 03 / 2001$ & 10,29 \\
$2001 / 2002$ & $22 / 03 / 2002$ & 9,40 \\
$2002 / 2003$ & $31 / 10 / 2002$ & 2,54 \\
$2003 / 2004$ & $16 / 03 / 2004$ & 19,74 \\
$2004 / 2005$ & $25 / 02 / 2005$ & 19,53 \\
$2005 / 2006$ & $09 / 02 / 2006$ & 18,81 \\
$2006 / 2007$ & $06 / 01 / 2007$ & 17,59 \\
$2007 / 2008$ & $07 / 03 / 2008$ & 11,35 \\
$2008 / 2009$ & $08 / 01 / 2009$ & 6,13 \\
\hline
\end{tabular}


(2 eventos), meses que, em geral, apresentam os maiores índices pluviométricos no DF. No entanto, dois valores de $\mathrm{Q}_{\text {maxinst }}$ foram observados em períodos de transição da época seca para a chuvosa - em outubro de 2002 e em novembro de 1998, coincidentemente, os anos hidrológicos de menor precipitação total anual (Tabela 1).

Comparando o menor valor de $\mathrm{Q}_{7}$ (Tabela 2) com o maior valor de $\mathrm{Q}_{\text {maxinst }}$ (Tabela 3), verifica-se que a amplitude de vazão na microbacia é de até 860 vezes. No entanto, as grandes vazões observadas no córrego não traduzem em riscos de inundação em áreas agrícolas situadas alguns quilômetros abaixo, haja visto o leito do córrego Capetinga estar situado num canal natural profundo e bem delimitado.

\section{Estudos de estacionariedade}

Os estudos de estacionariedade mostraram que as séries de precipitação total anual, vazão média de longa duração e vazão mínima com sete dias de duração apresentaram-se estacionárias
(Tabelas 4, 5 e 6, respectivamente), enquanto que a série de vazões máximas instantâneas não é estacionária (Tabela 7).

As probabilidades, no caso de estacionariedade da precipitação total anual, variaram entre 0,146 e 0,715 , ficando distantes do limite de $5 \%$ para considerar a série não estacionária. O mesmo ocorreu com as vazões média de longa duração e $\mathrm{Q}_{7}$ que obtiveram probabilidades de 0,554 a 0,978 e 0,572 a 0,968 , respectivamente.

No caso desta microbacia, compreendida em uma área de preservação ambiental, a estacionariedade dos parâmetros hidrológicos vazão média de longa duração e vazão mínima com sete dias de duração é explicada pela permanência da precipitação total anual, da vegetação natural dentro da microbacia, bem como a manutenção de suas características geológicas.

Com relação à estacionariedade da precipitação total anual, permite-se observar que o debatido aquecimento global não provocou, dentro do período estudado, alteração na precipitação na região.

Tabela 4. Estudo de estacionariedade da precipitação anual: subperíodos utilizados, variância $\left(\mathrm{s}^{2}\right.$, em $\mathrm{mm}^{2}$ ), média (em $\mathrm{mm}$ ) e níveis de probabilidade (P)

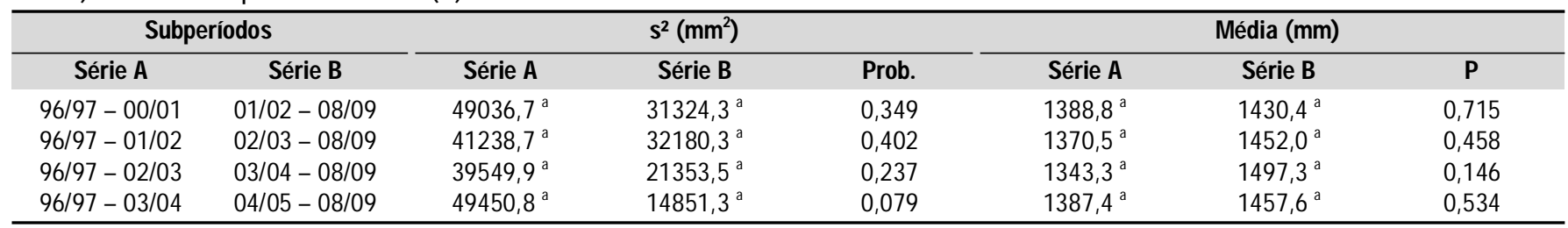

Variâncias e médias seguidas de letras iguais não diferem entre si estatisticamente pelo teste $\mathrm{F}$ e teste $\mathrm{t}$ a $5 \%$, respectivamente (comparação entre colunas)

Tabela 5. Estudo de estacionariedade da vazão média: subperíodos utilizados, variância $\left(\mathrm{s}^{2}\right.$, em $\left.\left(\mathrm{m}^{3} \mathrm{~s}^{-1}\right)^{2}\right)$, média ( $\mathrm{Xm}$, em $\mathrm{m}^{3} \mathrm{~s}^{-1}$ ) e níveis de probabilidade (P)

\begin{tabular}{|c|c|c|c|c|c|c|c|}
\hline \multicolumn{2}{|c|}{ Subperíodos } & \multicolumn{3}{|c|}{$s^{2}\left(m^{3} s^{-1}\right)^{2}$} & \multicolumn{3}{|c|}{$X m\left(m^{3} s^{-1}\right)$} \\
\hline Série $A$ & Série B & Série A & Série B & $\mathbf{P}$ & Série A & Série B & $\mathbf{P}$ \\
\hline $\begin{array}{l}96 / 97-00 / 01 \\
96 / 97-01 / 02 \\
96 / 97-02 / 03 \\
96 / 97-03 / 04\end{array}$ & $\begin{array}{l}01 / 02-08 / 09 \\
02 / 03-08 / 09 \\
03 / 04-08 / 09 \\
04 / 05-08 / 09\end{array}$ & $\begin{array}{l}0,00157^{a} \\
0,00126^{a} \\
0,00126^{a} \\
0,00117^{a}\end{array}$ & $\begin{array}{l}0,00006^{a} \\
0,00076^{a} \\
0,00059^{a} \\
0,00065^{a}\end{array}$ & $\begin{array}{l}0,146 \\
0,276 \\
0,190 \\
0,233\end{array}$ & $\begin{array}{l}0,1680^{a} \\
0,1683^{a} \\
0,1629^{a} \\
0,1663^{a}\end{array}$ & $\begin{array}{l}0,1675^{a} \\
0,1671^{a} \\
0,1733^{a} \\
0,1700^{a}\end{array}$ & $\begin{array}{l}0,978 \\
0,947 \\
0,554 \\
0,837\end{array}$ \\
\hline
\end{tabular}

Variâncias e médias seguidas de letras iguais não diferem entre si estatisticamente pelo teste $\mathrm{F}$ e teste $\mathrm{t}$ a $5 \%$, respectivamente (comparação entre colunas)

Tabela 6. Estudo da estacionariedade da série $Q_{7}$ anual: subperíodos utilizados, variância $\left(\mathrm{s}^{2}\right.$, em $\left.\left(\mathrm{m}^{3} \mathrm{~s}^{-1}\right)^{2}\right)$, média $(X \mathrm{~m}$, em $\mathrm{m}^{3} \mathrm{~s}^{-1}$ ) e níveis de probabilidade (P)

\begin{tabular}{|c|c|c|c|c|c|c|c|}
\hline \multicolumn{2}{|c|}{ Subperíodos } & \multicolumn{3}{|c|}{$s^{2}\left(m^{3} s^{-1}\right)^{2}$} & \multicolumn{3}{|c|}{$\mathrm{Xm}\left(\mathrm{m}^{3} \mathrm{~s}^{-1}\right)$} \\
\hline Série A & Série B & Série $A$ & Série B & $\mathbf{P}$ & Série A & Série B & $\mathbf{P}$ \\
\hline $\begin{array}{l}96 / 97-00 / 01 \\
96 / 97-01 / 02 \\
96 / 97-02 / 03 \\
96 / 97-03 / 04\end{array}$ & $\begin{array}{l}01 / 02-08 / 09 \\
02 / 03-08 / 09 \\
03 / 04-08 / 09 \\
04 / 05-08 / 09\end{array}$ & $\begin{array}{l}0,00008^{a} \\
0,00007^{a} \\
0,00006^{a} \\
0,00005^{a}\end{array}$ & $\begin{array}{l}0,00001^{b} \\
0,00001^{b} \\
0,00001^{b} \\
0,00000^{b}\end{array}$ & $\begin{array}{l}0,049 \\
0,013 \\
0,036 \\
0,001\end{array}$ & $\begin{array}{l}0,031^{a} \\
0,032^{a} \\
0,032^{a} \\
0,031^{a}\end{array}$ & $\begin{array}{l}0,031^{a} \\
0,031^{a} \\
0,030^{a} \\
0,031^{a}\end{array}$ & $\begin{array}{l}0,968 \\
0,664 \\
0,572 \\
0,957\end{array}$ \\
\hline
\end{tabular}

Variâncias e médias seguidas de letras iguais não diferem entre si estatisticamente pelo teste $\mathrm{F}$ e teste $t$ a $5 \%$, respectivamente (comparação entre colunas)

Tabela 7. Estudo de estacionariedade da Vazão M áxima Instantânea: subperíodos utilizados, variância $\left(\mathrm{s}^{2}, \mathrm{em}\left(\mathrm{m}^{3} \mathrm{~s}^{-1}\right)^{2}\right)$, média $\left(\mathrm{Xm}, \mathrm{em} \mathrm{m}^{3} \mathrm{~s}^{-1}\right)$ e níveis de probabilidade $(\mathrm{P})$

\begin{tabular}{|c|c|c|c|c|c|c|c|}
\hline \multicolumn{2}{|c|}{ Subperíodos } & \multicolumn{3}{|c|}{$\mathrm{s}^{2}\left(\mathrm{~m}^{3} \mathrm{~s}^{-1}\right)^{2}$} & \multicolumn{3}{|c|}{$\mathrm{Xm}\left(\mathrm{m}^{3} \mathrm{~s}^{-1}\right)$} \\
\hline Série $\mathbf{A}$ & Série $B$ & Série A & Série B & $\mathbf{P}$ & Série $\mathbf{A}$ & Série B & $\mathbf{P}$ \\
\hline $96 / 97-00 / 01$ & $01 / 02-08 / 09$ & $15,649^{a}$ & $45,005^{a}$ & 0,162 & $9,654^{a}$ & $13,136^{\mathrm{a}}$ & 0,320 \\
\hline $96 / 97-01 / 02$ & $02 / 03-08 / 09$ & $12,530^{\mathrm{a}}$ & $49,847^{a}$ & 0,076 & $9,612^{a}$ & $13,670^{a}$ & 0,230 \\
\hline $96 / 97-02 / 03$ & $03 / 04-08 / 09$ & $17,586^{\mathrm{a}}$ & $30,912^{a}$ & 0,256 & $8,601^{b}$ & $15,525^{a}$ & 0,027 \\
\hline $96 / 97-03 / 04$ & $04 / 05-08 / 09$ & $30,582^{a}$ & $33,310^{a}$ & 0,431 & $9,994^{\text {a }}$ & $14,682^{\text {a }}$ & 0,171 \\
\hline
\end{tabular}

Variâncias e médias seguidas de letras iguais não diferem entre si estatisticamente pelo teste $\mathrm{F}$ e teste t a $5 \%$, respectivamente (comparação entre colunas) 
No caso da vazão máxima instantânea, a série foi considerada não estacionária para os períodos 1997 a 2003 e 2004 a 2009, mostrando que houve uma alteração significativa nos valores de vazão máxima. Em todos os períodos analisados, as probabilidades foram mais baixas que dos outros estudos de estacionariedade, variando de 0,027 e 0,320 (Tabela 7). Pode-se assim observar que existe suscetibilidade das vazões máximas instantâneas aos fenômenos pontuais, dados pela característica das chuvas (total e intensidade) e umidade inicial no solo antecedente ao evento, por exemplo, sem necessariamente indicar que a não estacionariedade da série seja resultado de ações antrópicas na vizinhança.

\section{Análise das distribuições estatísticas usadas na previsão de eventos extremos}

Analisando o ajuste da série de vazões máximas instantâneas às distribuições apresentadas na Tabela 8 , nota-se que a distribuição Lognormal 3 apresentou a menor amplitude entre os intervalos de confiança superior e inferior, mostrando-se a mais adequada para o cálculo da vazão máxima instantânea com período de retorno de 100 anos $\left(\mathrm{Q}_{\max , 100}\right)$ no córrego Capetinga, vindo ao encontro dos resultados observados por Haktanir (1992). A distribuição Pearson 3 também poderia ser utilizada para esse fim uma vez que apresentou amplitudes e valor de $\mathrm{Q}_{\max , 100}$ próximos aos da distribuição Lognormal 3.

Tabela 8. D istribuições estatísticas usadas para cal cular a vazão máxima instantânea com período de retorno de 100 anos, respectivos val ores de $Q_{\text {max, } 100}\left(\mathrm{~m}^{3} \mathrm{~s}^{-1}\right)$, interval os de confiança e amplitude do intervalo

\begin{tabular}{lcccc}
\hline Distribuição & $\mathbf{Q}_{\text {max,100 }}$ & $\begin{array}{c}\text { Intervalo de } \\
\text { confiança } \\
\text { superior } \\
\mathbf{( 9 5 \% )}\end{array}$ & $\begin{array}{c}\text { Intervalo de } \\
\text { confiança } \\
\text { inferior } \\
\mathbf{( 9 5 \% )}\end{array}$ & $\begin{array}{c}\text { Amplitude } \\
\text { do } \\
\text { intervalo }\end{array}$ \\
Gumbel & 35,936 & 51,665 & 20,206 & 31,459 \\
Pearson 3 & 25,980 & 35,086 & 16,875 & 18,211 \\
Logpearson 3 & 93,306 & 270,445 & $-83,833$ & 354,278 \\
Lognormal 2 & 31,594 & 47,982 & 15,207 & 32,774 \\
Lognormal 3 & 25,717 & 34,487 & 16,947 & 17,540 \\
\hline
\end{tabular}

A distribuição que apresentou o pior ajuste para a série de vazões máximas foi a Logpearson 3. As distribuições de Gumbel e Lognormal 2 apresentaram ajustes intermediários, no entanto, ainda superestimaram o valor de $\mathrm{Q}_{\max , 100} \mathrm{em}$ relação ao valor ajustado pela distribuição mais adequada (Lognormal 3). Dessa forma, sugere-se o valor ajustado de $\mathrm{Q}_{\max , 100}$, considerando a distribuição mais adequada, igual a $25,717 \mathrm{~m}^{3} \mathrm{~s}^{-1}$ para o córrego Capetinga.

No caso da vazão mínima com sete dias de duração e período de retorno de 10 anos $\left(\mathrm{Q}_{7,10}\right)$, todas as distribuições testadas tiveram bom comportamento (Tabela 9); no entanto, o melhor ajuste se deu com a distribuição Logpearson 3, concordando com Reilly \& Kroll (2003) e Kroll et al. (2004). O pior ajuste encontrado foi o fornecido pela distribuição Lognormal 3, diferindo do obtido por Silva et al. (2006). No trabalho desses autores, foram aplicadas as distribuições de Gumbel, Weibull e Lognormal 3 na Nacia doAlto Rio Grande (MG) na determinação da $\mathrm{Q}_{7,10}$, e foi verificado que o melhor ajuste ocorreu com a última distribuição testada. Desta forma, infere-se que não há uma distribuição melhor que outra para todos os casos, e sim a melhor distribuição para cada caso. É também interessante observar que a distribuição que teve o melhor ajuste para os dados de vazão mínima foi a que se mostrou menos adequada para a vazão máxima, e vice versa. Pelos resultados alcançados, sugere-se para $Q_{7,10}$ o valor ajustado de $0,023 \mathrm{~m}^{3} \mathrm{~s}^{-1}$ para a bacia estudada.

Tabela 9. Distribuições estatísticas usadas para cal cular a vazão mínima com duração de sete dias e período de retorno de 10 anos, respectivos valores de $Q_{7,10}\left(\mathrm{~m}^{3} \mathrm{~s}^{-1}\right)$, intervalos de confiança e amplitude do intervalo

\begin{tabular}{lcccc}
\hline Distribuição & $\mathbf{Q}_{\mathbf{7}, 10}$ & $\begin{array}{c}\text { Intervalo de } \\
\text { confiança } \\
\text { superior } \\
\mathbf{( 9 5 \% )}\end{array}$ & $\begin{array}{c}\text { Intervalo de } \\
\text { confiança } \\
\text { inferior } \\
\mathbf{( 9 5 \% )}\end{array}$ & $\begin{array}{c}\text { Amplitude } \\
\text { do } \\
\text { Intervalo }\end{array}$ \\
Weibull & $\mathbf{0 , 0 2 3}$ & $\mathbf{0 , 0 2 7 1}$ & 0,0182 & 0,0089 \\
Pearson 3 & 0,023 & 0,0275 & 0,0175 & 0,0100 \\
Logpearson 3 & 0,023 & 0,0263 & 0,0205 & 0,0058 \\
Lognormal 2 & 0,023 & 0,0270 & 0,0193 & 0,0077 \\
Lognormal 3 & 0,021 & 0,0257 & 0,0156 & 0,0101 \\
\hline
\end{tabular}

Comparação entre os resultados de uma série média e uma série curta de vazão

Os valores das vazões $\mathrm{Q}_{7}$ e $\mathrm{Q}_{\text {maxinst }}$ para as duas séries (curta e média) e diversos períodos de retorno estão apresentados nas Tabelas 10 e 11, respectivamente. No caso de $\mathrm{Q}_{7}$ verificouse superestimativa, variando de 3,8 a $13,0 \%$ nos valores ajustados pela distribuição de Logpearson 3 , quando se usa a série curta em detrimento da média, para períodos de retorno de 5 e 100 anos respectivamente, o que evidencia a vantagem de se usar séries mais longas, quando disponíveis.

No caso da vazão máxima instantânea a variação entre as séries foi mais significativa, chegando à diferença de 37,3\% entre os valores de vazão. Ao contrário da vazão mínima, a

Tabela 10. Vazões mínimas com sete dias de duração $\left(Q_{7}, e^{3} \mathrm{~m} \mathrm{~s}^{-1}\right)$ ajustadas pela distribuição de Logpearson 3 utilizando séries de dados curtas e médias, para diferentes períodos de retorno, e variação entre as séries $(\Delta$, em $\%)$

\begin{tabular}{cccc}
\hline $\mathbf{T}$ (anos) & $\begin{array}{c}\mathbf{Q}_{\mathbf{7}} \\
\text { série média }\end{array}$ & $\begin{array}{c}\mathbf{Q}_{\mathbf{7}} \\
\text { série curta }\end{array}$ & $\boldsymbol{\Delta}$ \\
5 & 0,025 & 0,026 & 3,8 \\
10 & 0,023 & 0,025 & 8,0 \\
20 & 0,022 & 0,024 & 8,3 \\
50 & 0,021 & 0,023 & 8,7 \\
100 & 0,020 & 0,023 & 13,0 \\
\hline
\end{tabular}

Tabela 11. Vazões máximas instantâneas $\left(Q_{\text {maxinst' }}\right.$ em $\mathrm{m}^{3} \mathrm{~s}^{-1}$ ) ajustadas pela distribuição Lognormal 3, utilizando séries de dados curtas e médias, para diferentes tempos de retorno, e variação entre as séries $(\Delta$, em \%)

\begin{tabular}{rccc}
\hline T (anos) & $\begin{array}{c}\mathbf{Q}_{\text {maxinst }} \\
\text { série média }\end{array}$ & $\begin{array}{c}\mathbf{Q}_{\text {maxinst }} \\
\text { série curta }\end{array}$ & $\boldsymbol{\Delta}$ \\
5 & 16,728 & 12,508 & 33,7 \\
10 & 19,367 & 14,248 & 35,9 \\
20 & 21,562 & 15,751 & 36,9 \\
50 & 24,049 & 17,517 & 37,3 \\
100 & 25,717 & 18,741 & 37,2 \\
\hline
\end{tabular}


série média apresentou maiores valores de vazão máxima que a série curta, mostrando que o uso desta conduz à subestimativa das vazões.

A pequena variação observada nas vazões mínimas ajustadas nas duas séries usadas é decorrente do fato destas terem sido estacionárias, assim como a precipitação total anual, da qual as vazões mínimas são mais dependentes. No caso das vazões máximas, a variação verificada entre as duas séries foi maior, decorrente da não estacionariedade das mesmas, que são mais dependentes da precipitação causadora do evento.

Para reduzir os riscos na gestão de recursos hídricos, é preferível usar metodologias que subestimem as vazões mínimas ao invés de superestimá-las, da mesma forma que é menos arriscado superestimar vazões máximas em prol de subestimá-las, razão pela qual deve ser dada preferência ao uso de séries mais longas.

No caso da vazão média de longa duração, não foi observada diferença entre as duas séries sendo a $Q_{\text {mld }}$ igual a $0,167 \mathrm{~m}^{3} \mathrm{~s}^{-1}$ nos dois casos. Este resultado é coerente, devido à estacionariedade da precipitação total anual, e de Q.

\section{Possibilidades de outorga do uso da água no córrego Capetinga}

A Tabela 12 apresenta os valores das vazões mínimas de referência para a concessão de outorgas no córrego Capetinga e os respectivos limites de concessão para uso coletivo e para uso individual.

Tabela 12. Vazões mínimas de referência e limites de concessão de outorga no córrego Capetinga

\begin{tabular}{cccc}
\hline Vazão de & Valor total & Uso coletivo* & Uso individual** \\
\cline { 2 - 4 } referência & \multicolumn{3}{|}{$\left(\mathbf{L} \mathbf{~ s}^{-1} \mathbf{)}\right.$} \\
$\mathbf{Q}_{7,10}$ & 23,00 & 18,40 & 3,68 \\
$Q_{90}$ & 37,00 & 29,60 & 5,92 \\
$Q$ & 49,00 & 39,20 & 7,84 \\
\hline
\end{tabular}

* Uso coletivo $=80 \%$ das vazões de referência, 0 que corresponde à vazão máxima outorgável, resultado da soma das vazões a serem outorgadas em um mesmo curso de água

** Uso individual $=20 \%$ da vazão máxima outorgável

Os valores limites de concessão de vazão para uso individual no córrego Capetinga, sem a adoção de armazenamento em barragens, foram relativamente baixos (variação de 3,68 a 7,84 $\mathrm{L} \mathrm{s}^{-1}$ ), mostrando que o córrego tem pouco potencial para a exploração de seus recursos hídricos. No entanto, valores dessa magnitude estão acima do considerado como insignificante pela $\operatorname{ADASA}\left(1 \mathrm{~L} \mathrm{~s}^{-1}\right)$, o que implica na dependência do pedido de outorga para a captação de água no córrego Capetinga, nas quantidades mencionadas. O limite máximo de captação para uso na área experimental irrigada na Fazenda Água Limpa é de $17,0 \mathrm{~L} \mathrm{~s}^{-1}$, o que está abaixo do limite máximo outorgável para uso coletivo, não comprometendo ambientalmente o córrego.

\section{Conclusões}

1. A estacionariedade verificada na vazão mínima da microbacia estudada reforça a importância de áreas de proteção ambiental no controle do meio ambiente.

2. A distribuição estatística que se mostrou mais adequada aos eventos de vazões mínimas foi a Logpearson 3, enquanto que para as vazões máximas, as distribuições adequadas foram a Lognormal 3 e a Pearson 3.

3. O uso de séries curtas de vazões em detrimento das séries médias não se mostrou adequado para o gerenciamento dos recursos hídricos da microbacia, principalmente no caso das vazões máximas.

4. O limite de vazão outorgável no córrego Capetinga é baixo, restringindo o crescimento das áreas irrigadas da Fazenda Experimental Água Limpa.

\section{Agradecimentos}

Agradecemos à Fundação de Apoio à Pesquisa do Distrito Federal (FAP-DF) pelos recursos utilizados na instalação da estação hidrológica no córrego Capetinga.

\section{LITERATURA CITADA}

Alencar, D. B. S.; Silva, C. L.; Oliveira, C. A. S. Influência da precipitação no escoamento superficial em uma microbacia hidrográfica do Distrito Federal. Engenharia Agrícola, v.26, p.103-112, 2006.

Chow, V. T.; Maidment, D. R.; Mays, L. W. Applied hydrology. 1.ed. New York: Mc Graw-Hill Publishing Company, 1988. $572 \mathrm{p}$.

Dornelas, K. D. S.; Silva, C. L.; Oliveira, C. A. S. Coeficientes médios da equação de Angström-Prescott, radiação solar e evapotranspiração de referência em Brasília. Pesquisa Agropecuária Brasileira, v.41, p.1213-1219, 2006.

Groppo, J. D.; Moraes, J. M. de; Beduschi, C. E.; Martinelli, L. A. Analysis of time series of flow and precipitation in some basins of the São Paulo State with different degrees of human impact. Geociências, v.24, p.181-192, 2005.

Haktanir, T. Comparison of various flood frequency distributions using annual flood peaks data of rivers in Anatolia. Journal of Hydrology, v.136, p.1-31, 1992.

Hannaford, J.; Marsh, T. An assessment of trends in UK runoff and low flows using a network of undisturbed catchments. International Journal of Climatology, v.26, p.1237-1253, 2006.

Kite, G. W. Frequency and risk analyses in hydrology. 5.ed. Highlands Ranch, Colorado: Water Resources Publications, 1988. 257p.

Kroll, C.; Luz, J.; Allen, B.; Vogel, R. M. Developing a watershed characteristics database to improve low streamflow prediction. Journal of Hydrologic Engineering, v.9, p.116125, 2004.

Kroll, C. N.; Vogel, R. M. Probability distribution of low streamflow series in the United States. Journal of Hydrologic Engineering, v.7, p.137-146, 2002.

Leme, E. J. A. Hidrologia estatística da vazão mínima do rio Jaguari Mirim. Revista Ecossistema, v.27, p.77-81, 2002.

Leme, E. J. A.; Chaudhry, F. H. Vazão mínima do vale médio do rio Jaguari Mirim. Revista Brasileira de Recursos Hídricos, v.10, p.127-136, 2005. 
Müller, I. I.; Krüger, C. M.; Kaviski, E. Análise de estacionariedade de séries hidrológicas na bacia incremental de Itaipu. Revista Brasileira de Recursos Hídricos, v.3, p.5171, 1998.

Rebouças, A. C.; Braga, B.; Tundisi, J. G. Águas doces no Brasil: capital ecológico, uso e conservação. São Paulo: Escrituras Editora, 1999. 717p.

Reilly, C. F.; Kroll, C. N. Estimation of 7-day, 10-year lowstreamflow statistics using baseflow correlation. Water Resources Research, v.39, p.1236-1245, 2003.

Sánchez-Román, R. M; Folegatti, M. V.; Orellana-González, A. M. G. Situação dos recursos hídricos nas bacias hidrográficas dos rios Piracicaba, Capivari e Jundiaí utilizando modelo desenvolvido em dinâmica de sistemas. Engenharia Agrícola, v.29, p.578-590, 2009.
Silva, A. M.; Oliveira, P. M.; Mello, C. R.; Pierangeli, C. Vazões mínimas e de referência para outorga na região do Alto Rio Grande, Minas Gerais. Revista Brasileira de Engenharia Agrícola eAmbiental, v.10, p.374-380, 2006.

Silva, C. L. Análise estatística das características de vazão do córrego Capetinga. Revista Brasileira de Engenharia Agrícola eAmbiental, v.7, p.311-317, 2003.

Silva, C. L.; Oliveira, C. A. S. Runoff measurement and prediction for a watershed under natural vegetation in central Brazil. Revista Brasileira de Ciência do Solo, v.23, p.695-701, 1999.

Sousa, H. T.; Pruski, F. F.; Bof, L. H. N.; Cecon, P. R.; Souza, J. R. C. SisCAH 1.0: Sistema computacional para análises hidrológicas. Brasília: Agência Nacional de Águas, Viçosa: Universidade Federal de Viçosa, 2009. 60p.

Tucci, C. E. M. Regionalização de vazões. Porto Alegre: Universidade Federal do Rio Grande do Sul, 2002. 256p. 